\begin{tabular}{|c|c|}
\hline PORT SAID ENGINEERING RESEARCH JOURNAL \\
Faculty of Engineering - Port Said University \\
Volume 17 No. 1 pp: 1:7
\end{tabular}

\title{
Numerical Simulation of Methane Combustion with and without Radiation Models
}

\author{
Shabaan M. M and Ibrahim I. A.
}

\begin{abstract}
The present work is a numerical simulation results from the modelling of a non-premixed methane fl ame with and without radiation models. CFD studies using FLUENT code were carried out for three cases; without radiation model, with the P-1 radiation model and with the discrete transfer radiation model. The model results from these three cases are compared with each other and with the experimental results. The discrete transfer and of the P-1 radiation models are assessed in a swirling methane non-premixed flame confined in an axisymmetric combustor. The predictions are involving the modeling of the combustion and radiation phenomena. Computational results with and without radiation effects are compared with experimental data and the two radiation models are evaluated in terms of computational efficiency, ease of application and predictive accuracy. The effects of momentum flux, swirl number and air inlet temperature on flame characteristics are examined. A comparison of realizable k- $\varepsilon$ and standard k- $\omega$ turbulent models are presented. The results show the significant effect of studied parameters on the flame characteristics and temperature patterns. The results have demonstrated that the effect of thermal radiation is important even in flames, and that the discrete transfer and the P-1 radiation models and realizable k- $\varepsilon$ turbulent model can be applied in industrial gas furnaces with relative ease, yielding accurate predictions.
\end{abstract}

\section{Introduction}

Diffusion flames have been widely applied in industrial process systems, such as burners and furnaces. Both numerical and experimental investigations of turbulent diffusion (non-premixed) flames have been the subject of extensive research during recent years for several gas fuels and liquid fuels, because they are very important for the understanding of complex interactions between the turbulent flow and chemical reactions [1,6]. Ilbas et al [1] performed the numerical simulation of a turbulent nonpremixed hydrogen diffusion flame in a model combustor. The model prediction studies have been extended to combustion air staging. Air $25 \%$ was staged and introduced through the two tangential inlets. The temperature and major pollutant concentration $(\mathrm{CO}$ and NOx) distribution are in good agreement with experimental measurements. Computational fluid dynamics (CFD) has proven being a valuable tool in optimizing combustion equipments and natural gas burners, especially. There are several commercial software packages applied widely in research and development. For the simulation of a turbulent nonpremixed flame, several models are available. Thermal radiation in gaseous media can be an important mode of heat transfer in high temperature combustion systems, such as combustors, furnaces and fires. Radiation exchange plays a very important role even under non-soot conditions. Although computational fluid dynamics (CFD) has become a widely used and reliable tool to Corresponding author: E-mail: hema_bb76@yahoo..com support researchers and designers in the characterization, surfaces [2, 10 and 12]. Understanding and optimization of energy devices, radiation is often neglected among the complex flow, thermo-kinetic and convection phenomena. This is primarily associated with the high computational cost linked with the solution of the radiation equations, the signifi cant uncertainty in relation to the properties of the participating media and the optical properties of involved. The solution of reactive flow problems with radiative heat transfer requires a radiation model which is simultaneously accurate, fast and compatible with the algorithm employed to solve the transport equations. A review of the most commonly used methods to predict radiative heat transfer in combustion chambers is presented by [4]. Thermal radiation affects the structure and extinction characteristics of hydrocarbon fuels [5]. Turbulent diffusion flames are investigated numerically using a finite volume method for the solution of the conservation equations and reaction equations governing the problem. The standard $k-\varepsilon$ model was used for the modelling of the turbulence phenomena in the combustor [6]. Continuous combustion processes, such as those occurring in a gas turbine combustor, require the flame to be anchored at a zone within the flow field. In order to stabilize the flame, the incoming high-speed air stream must be decelerated to a velocity below the turbulent flame speed. The flame stabilizes along the locus of points where the air velocity is equal to the flame speed [7, 8]. At a certain point downstream, the low pressure region causes the vortex to collapse inwards on itself in a 
process known as vortex breakdown. This creates a recirculation zone in the centre of the flow. This is essential to provide sufficient time, temperature and turbulence for a complete combustion of the fuel [9]. Experimental investigations in [11] show that increasing fuel content in the mixture, velocity and temperature fields are changing considerably. Several analytical methods have been developed to support the engineering treatment of radiative heat transfer. Radiation models are mostly tested separately, in isolation of other physical processes [6-12]. Keramida et al [13] confined the performance of the discrete transfer and six flux radiation models in a swirling natural gas diffusion flame in axsymmetric furnace. Computational results with and without radiation effects are compared with experimental data. The results have demonstrated that the effect of thermal radiation is important even in lights flames, and that the six flux model can be applied in industrial gas furnaces with relative ease, yielding accurate predictions.

Mustafa Ilbas [14] presented a numerical simulation results from the modeling of turbulent non-premixed hydrogen - hydrocarbon flame with and without radiation models. The model results are compared with each other and with experimental data. Ilbas investigated the effect of fuel composition from pure natural gas to hydrogen.

The overall flame temperature increase as hydrogen is added or decrease as methane is added to the fuel mixture. The addition of methane to hydrogen decreases. The flame temperature and thus NOx emissions through the combustion exit. Iker and Ilbas [15] presented temperatures distributions from turbulent chemical reactive flow inside a model combustor for various mixture of hydrogen - methane fuels. They obtained the gas emissions at the combustor exit. The results show that the temperature level increase, $\mathrm{CO}$ and $\mathrm{CO}_{2}$ emissions decrease when the hydrogen content is increased in mixture fuel. The present work is amid to validate and simulate a non-premixed methane fl ame with and without radiation models in furnaces.

\section{Turbulence Model}

In the present work the so-called realizable $k-\varepsilon$ turbulence model provided by FLUENT code [16] are used. The realizable $k-\varepsilon$ model is a relatively recent development and differs from the standard $k-\varepsilon$ model in two important ways:

- The realizable $k$ - $\varepsilon$ model contains a new formulation for the turbulent viscosity.

- A new transport equation for the dissipation rate, $\varepsilon$, has been derived from an exact equation for the transport of the mean-square vorticity fluctuation.

The term "realizable" means that the model satisfies certain mathematical constraints on the Reynolds stresses, consistent with the physics of turbulent flows. An immediate benefit of the realizable $k-\varepsilon$ model is that it more accurately predicts the spreading rate of both planar and round jets. It is also likely to provide superior performance for flows involving rotation, boundary layers under strong adverse pressure gradients, separation, and recirculation.

\section{Radiation Models}

FLUENT provides four radiation models, which are discrete transfer radiation model (DTRM), P-1 radiation model, Rosseland radiation model, and Discrete ordinates (DO) radiation model. The radiative transfer equation (RTE) for an absorbing, emitting, and scattering medium at position $\mathrm{r}$ in the direction $\mathrm{s}$ is

$\begin{array}{ll}\frac{d I(r, s)}{d s}+\left(a+\sigma_{s}\right) I(I, s)=a n^{2} \frac{\sigma_{s}}{4 \pi} \int_{0}^{4 \pi} I(r, s) \Phi\left(s . s^{\prime}\right) d \Omega^{\prime} \\ \mathrm{r} & \begin{array}{l}\text { position vector } \\ \text { direction vector }\end{array} \\ \mathrm{s} & \begin{array}{l}\text { scattering direction vector } \\ \mathrm{s}^{\prime}\end{array} \\ \mathrm{s} & \text { path length } \\ \mathrm{a} & \text { absorption coefficient } \\ \mathrm{n} & \text { refractive index } \\ \sigma_{s} & \text { Scattering coefficient } \\ \sigma & \text { Stefan-Boltzmann constant }\left(5.67 * 10-8 \mathrm{~W} / \mathrm{m}^{2} \mathrm{~K}^{4}\right) \\ \mathrm{I} & \text { total radiation intensity, which depends on } \\ \mathrm{position} \text { (r) and direction (s) } \\ \mathrm{T} & \text { local temperature } \\ \Phi & \text { Phase function } \\ \Omega^{g} & \text { Solid angle } \\ \left(\mathrm{a}+\sigma_{s}\right) & \text { the optical thickness or opacity of the medium. }\end{array}$

\section{Computational details}

\subsection{Furnace configuration}

The domain of the model was based on the dimension of the combustor and burners. The case studied is a cylindrical enclosure of $0.15 \mathrm{~m}$ radius and $0.9 \mathrm{~m}$ length. Two reactant streams emerge from two separate coaxial jets producing a swirling diffusion flame. The fuel is injected from the central jet whereas the combustion air enters from the outer annular jet. The geometry of this furnace is illustrated in Fig. 1.

\subsection{Grid System}

Figure 2 shows the domain which used to simulate the combustor. The domain consists of an axisymmetric plane has dimensions which the same as the combustor; the region of interest is that just above the exits of the burners. An unstructured grid has been created using the GAMBIT pre-processor to discretize the computational domain [17]; the cell type used is the Quad-Map cell, the grid lines were non-uniformly spaced on both radial and axial direction as shown in Fig. 2. Grid independence tests for three different mesh sizes were carried out. The mesh sizes 28350, 15900 and 12000 cells. The influence of the mesh refinement on the distribution of the temperature along the axis of the combustor is shown in Fig. 3. The results indicate that increasing the grid size from 12000 to 28350 has lead to around $1 \%$ difference in the temperature. Considering the computational expense 
and time, the grid with for the entire domain are used for making the grid analysis. The grid with 15900 cells is considered for further analysis since the flow parameters are found to be independent of mesh size. Thus, the mesh of 15900 was considered suitable for the present calculations.

\section{Validation}

In order to validate the computational procedure, comparison of the present calculations with the experimental data reported by Keramida et al [13] was performed. The experimental data were obtained for the combustion process inside furnace of diameter of $d=0.3$ $\mathrm{m}$ and $0.9 \mathrm{~m}$ length. Methane gas at a velocity of 15 $\mathrm{m} / \mathrm{sec}$. was burned with air at an axial velocity of $12.28 \mathrm{~m}$ /s with swirl number of 0.4. A numerical experiment is carried out, using two different radiation models to analyze the radiative heat transfer in an industrial naturalgas furnace configuration. Comparisons between the experimental data reported by [13] and the calculated results obtained with and without radiation for the radial profiles of the temperature are shown in Figs.4-5. Two consecutive axial locations of $\mathrm{x}=0.2$ and $0.4 \mathrm{~m}$ one near the inlets and one near the middle of the furnace, while the variation of temperature along the furnace centreline is shown in Fig.6. It is shown that accounting for radiation in the computational analysis has produced better agreement between the predictions and the experimental data.

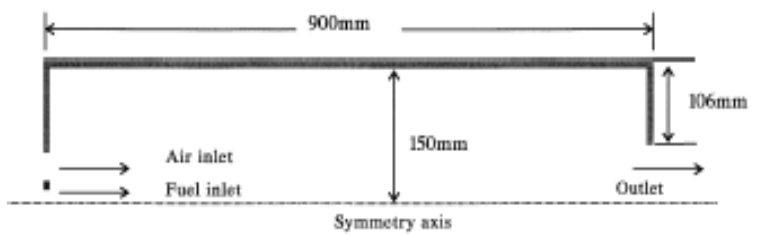

Fig. 1 Geometry of the combustion chamber.

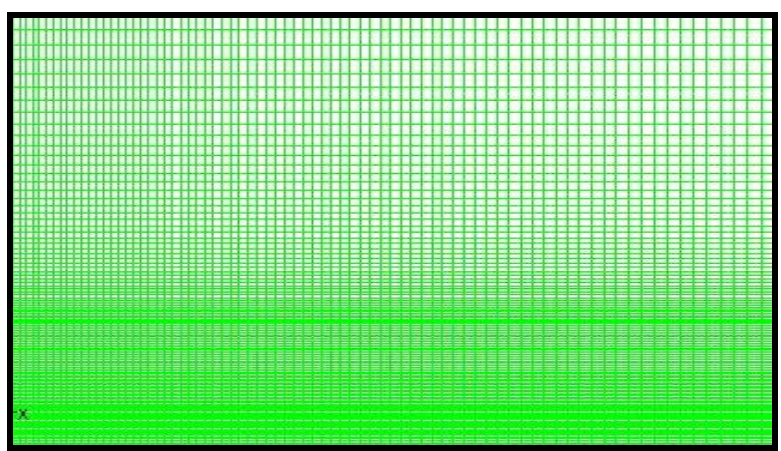

Fig. 2 Part of grid system

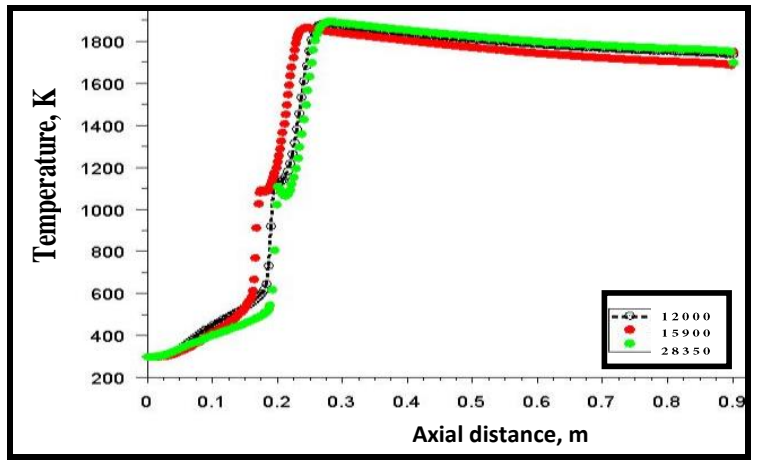

Fig. 3 Axial temperature at different mesh sizes

The reduction of the mean temperature in the furnace is significant. In the main combustion zone, where higher temperatures are reached, the effects of radiation are more evident and extend all over the furnace diameter at $\mathrm{x}=0.2$ $\mathrm{m}$ and $\mathrm{x}=0.4 \mathrm{~m}$. No significant differences are observed between the predicted temperatures with the two radiation models. Despite the fact that the overall heat released is the same in all the examined cases, radiative heat transfer is responsible for reducing the size of the high temperature regions of the flame and for shifting them towards the furnace inlet, as it is shown by the temperature maps in Fig. 7. A comparison of realizable k- $\varepsilon$ and standard k- $\omega$ turbulent models with measured axial temperature using P-1 mode is shown in Fig. 8. While comparison of realizable k- $\varepsilon$ model and standard $\mathrm{k}-\omega$ model with measured temperature at $\mathrm{x}=0.2 \mathrm{~m}$ (no radiation model) is shown in Fig. 9. From these figures there is no big advantage over each of radiation and turbulence models, in terms of predictive accuracy, except the model simplicity and low computational requirements of the P-1 model and realizable $\mathrm{k}-\varepsilon$ turbulent model. Finally, the two radiation models have performed similarly. This can be explained by the fact that there is a relative uniformity in the combustion gases concentration field encountered in a natural gas-fired furnace. So the P1 radiation model and realizable k- $\varepsilon$ turbulent model was chosen for the following calculations.

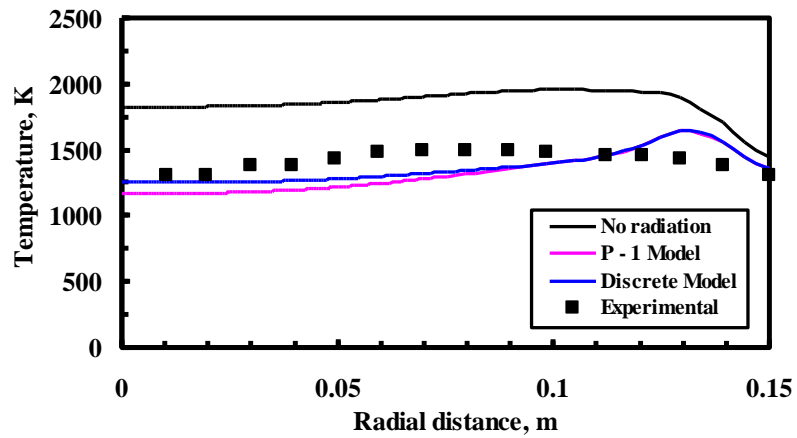

Fig.4. Comparison of calculated and measured temperature distributions at $\mathrm{x}=0.2 \mathrm{~m}$. 


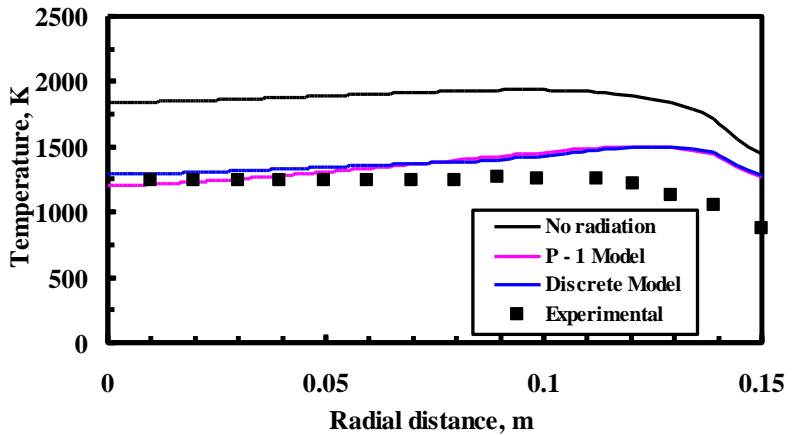

Fig.5. Comparison of calculated and measured temperature distributions at $x=0.4 \mathrm{~m}$.

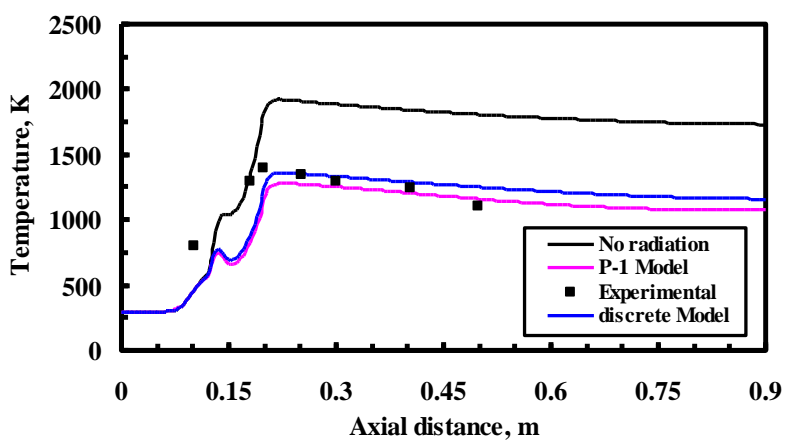

Fig.6. Comparison of calculated and measured axial temperature

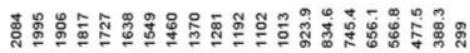

(a)

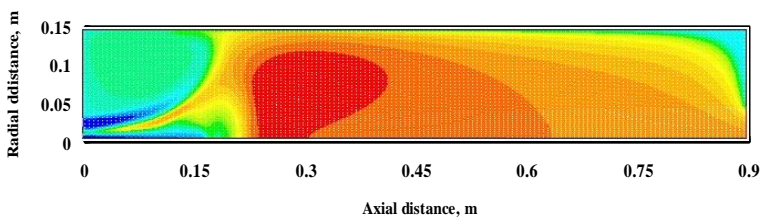

(b)

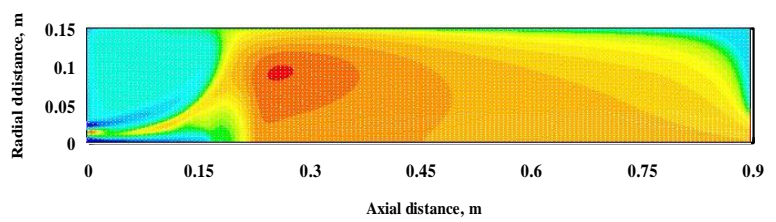

(c)

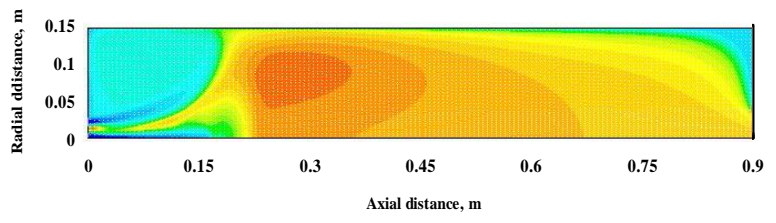

Fig.7 Temperature map $\left({ }^{\circ} \mathrm{K}\right)$ (a) No radiation, (b) Discrete model and (c) P-1 model

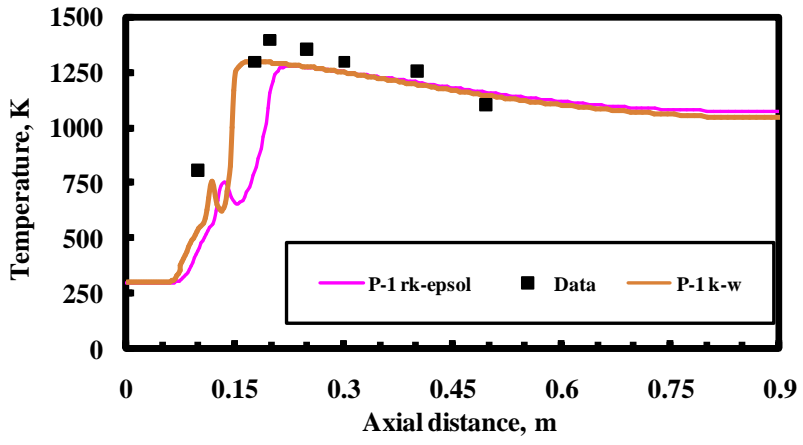

Fig.8 Comparison of Realizable k- $\varepsilon$ model and Standard k- $\omega$ model with measured axial temperature (P-1 model)

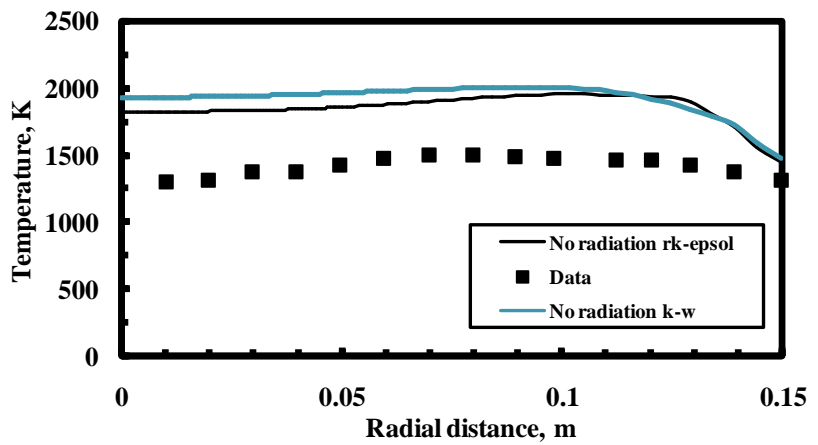

Fig.9 Comparison of Realizable k- $\varepsilon$ model and Standard k- $\omega$ model with measured temperature at $\mathbf{x}$ $=0.2 \mathrm{~m}$ (no radiation model)

\section{Results and discussions}

The effect of changing fuel mass flow rate on temperature maps, the axial temperature distributions, the mass fractions of $\mathrm{CO}_{2}$ and $\mathrm{O}_{2}$ maps, the axial mass fraction of $\mathrm{CO}_{2}$ and $\mathrm{O}_{2}$ are shown in figures 10-15, with constant air mass flow rate and constant air swirl number of 0.4. It is shown that, by increasing momentum flux (i.e. fuel mass flow rate), the fuel momentum increased due to increase in fuel velocity, so that, the high temperatures regions shifted downstream and inward. Also, the axial temperature increased with increasing the fuel mass flow rate as well as the flame length. The prediction distributions of mass fraction for $\mathrm{CO}_{2}$ and $\mathrm{O}_{2}$ show similar trends with temperature, namely the higher the local temperature the stronger the main products formation. This is due to the local temperature directly affects the component rates of production and consumption. 

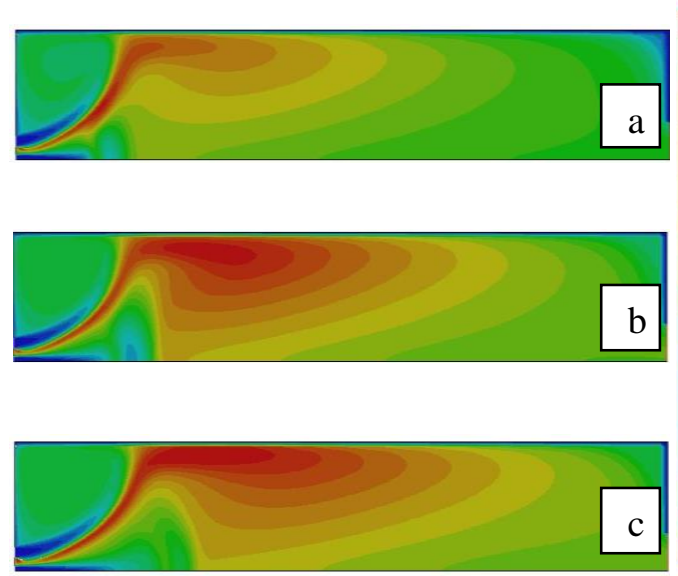

Fig.10 Temperature map $\left({ }^{\circ} \boldsymbol{K}\right)(\boldsymbol{a}) m_{f}=0.89 \mathrm{gm} / \mathrm{s},(\boldsymbol{b})$

$$
m_{f}=1.1 \mathrm{gm} / \mathrm{s} \text { and }(\boldsymbol{c}) m_{f}=1.5 \mathrm{gm} / \mathrm{s}
$$

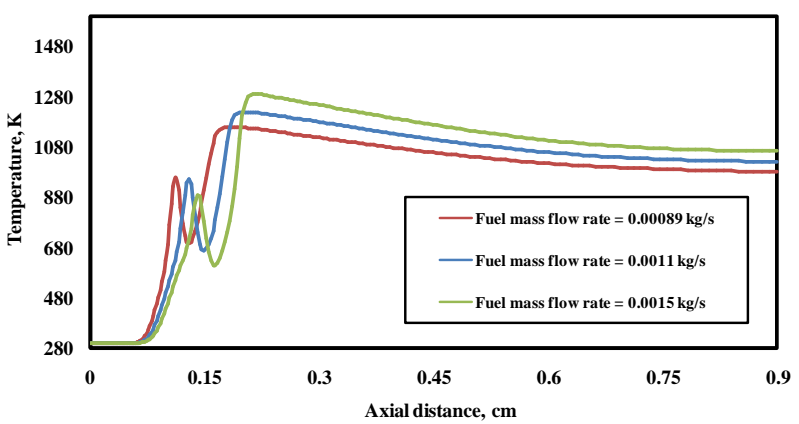

Fig.11 Axial temperature at different fuel mass flow rate
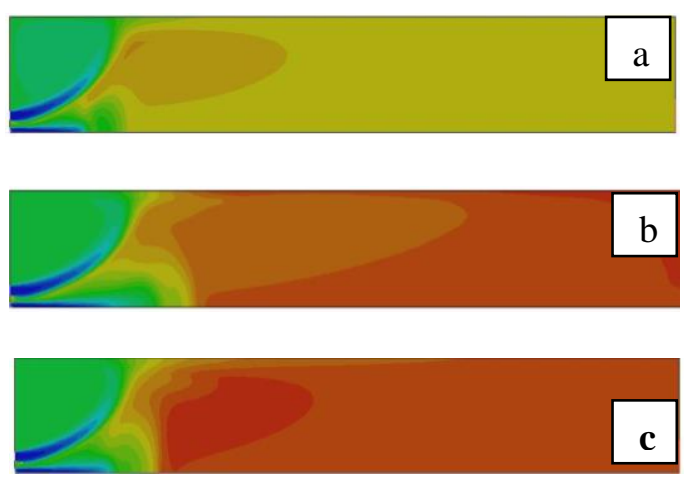

Fig.12 Carbon dioxide mass fraction map

a) $m_{f}=0.89 \mathrm{gm} / \mathrm{s}$, (b) $m_{f}=1.1 \mathrm{gm} / \mathrm{s}$ and (c) $m_{f}=1.5 \mathrm{gm} / \mathrm{s}$

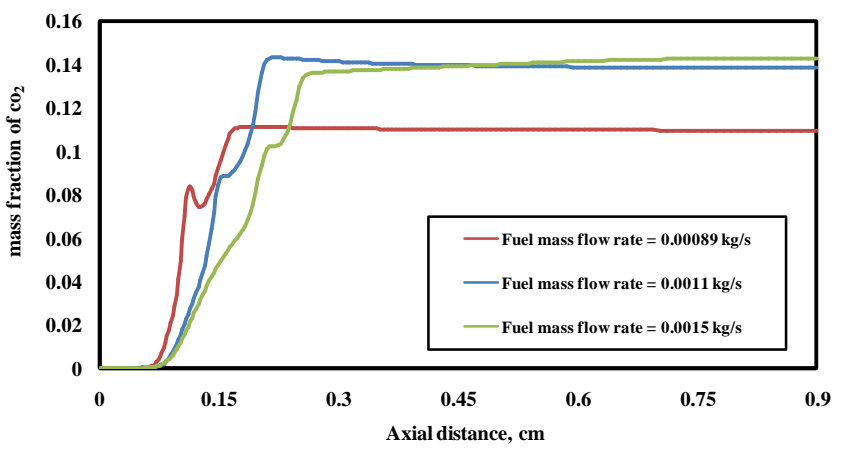

Fig.13 Axial carbon dioxide mass fraction at different fuel mass flow rate

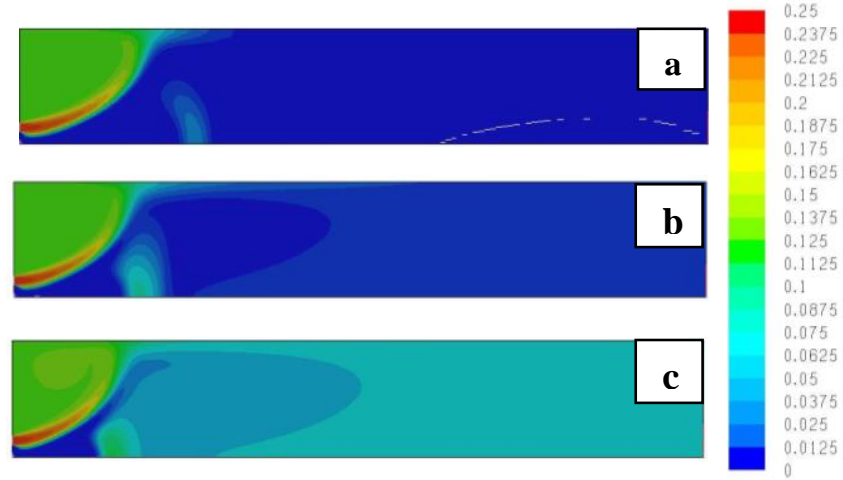

Fig.14 Oxygen mass fraction map a) $m_{f}=0.89 \mathrm{gm} / \mathrm{s}$,

(b) $m_{f}=1.1 \mathrm{gm} / \mathrm{s}$ and $(\boldsymbol{c}) m_{f}=1.5 \mathrm{gm} / \mathrm{s}$

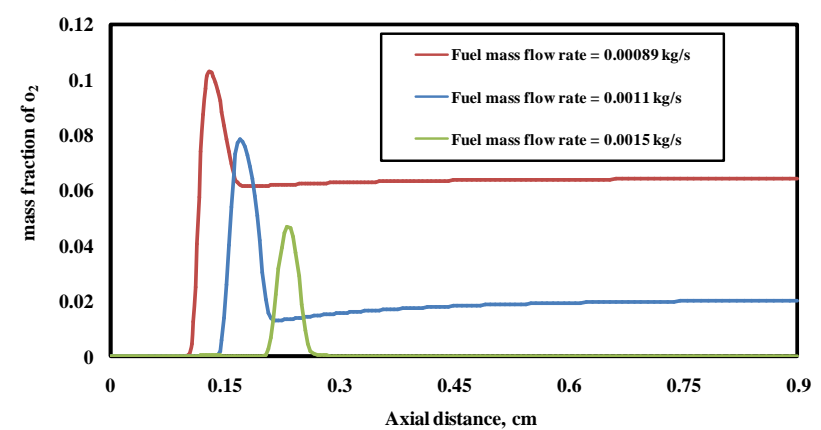

Fig.15 Axial oxygen mass fraction at different fuel mass flow rate

To study the effect of air swirl number on temperature patterns, fuel flow rate are maintained without changing $1.1 \mathrm{gm} / \mathrm{s}$. Tests are carried out on three air swirlers which having swirl numbers of $0.4,0.81$, and 1.22 . Three runs are carried in order to quantify the air swirl number effect on the temperature patterns. During these runs, the other operating conditions are remains constants such as air to fuel mass ratio (one air to fuel mass ratio is used). Fig. 16 shows the temperature maps for air swirl numbers of 0.4 , 0.81 and 1.22 and at constant air to fuel mass ratio. It is shown that, a low temperatures region is found nearest to the swirler at swirl number of 0.4 this low temperatures region is due the high axial air velocity. Increasing the air swirl number, high temperatures region shifted upstream 
direction nearer to air swirler. It can be explained that, increasing the air swirl number, the recirculation zone became stronger and the mixing rate increased results in small flame size, i.e., shorter flame length but wider flame diameter. The effect of changing the inlet air temperature on temperature maps is shown in Fig.17. From the observation of this figure it can be seen that: increasing the inlet air temperature from $280-320 \mathrm{~K}$ leads to decreasing the flame length and the maximum temperature region is shifted up stream.
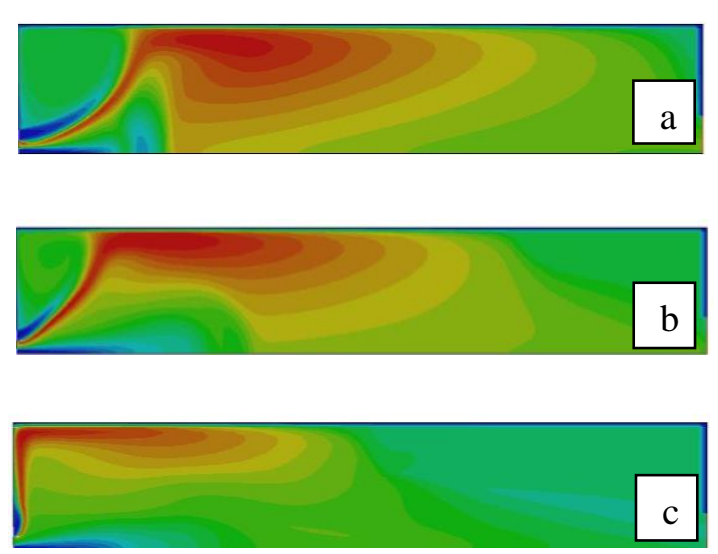

Fig.16 Temperature map $\left({ }^{\circ} \mathrm{K}\right)(\boldsymbol{a}) S w=0.4$, (b)

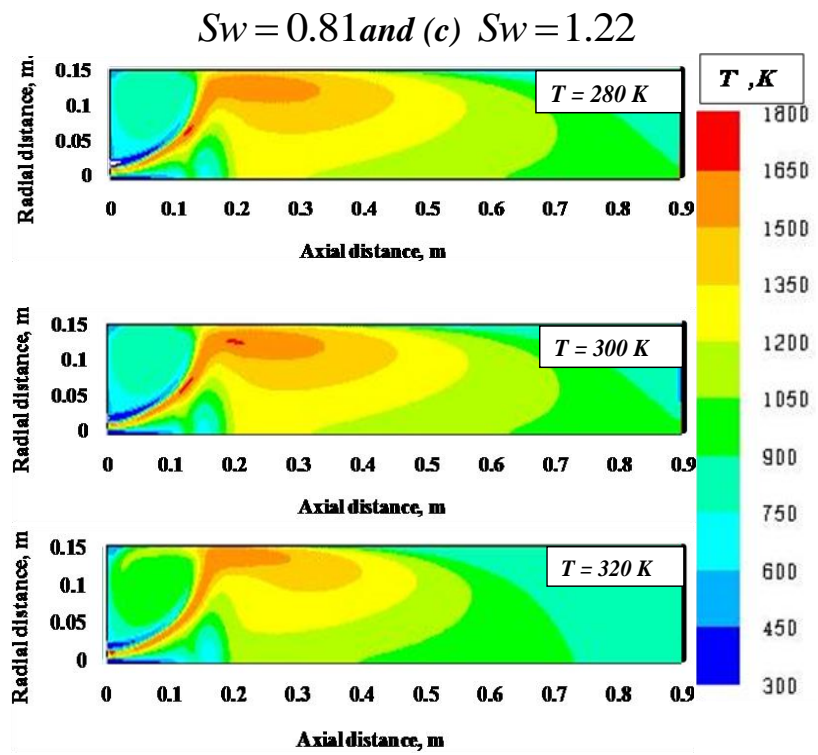

Fig.17 Effect of air inlet temperature on temperature map

\section{Conclusions}

The present work examined numerically a non-premixed, methane gas flame with no radiation, with the discrete heat transfer and the P-1 radiation models. From the results the following conclusions are presented:

- The effect of radiation is significant on flame temperature calculations.
- Using of radiative heat transfer in the combustion analysis has produced a better agreement between numerical predictions and experimental data.

- The maximum predicted temperature levels without radiation were higher than those predicted with any the two radiation models.

- The existing of radiative heat transfer reduced the size of the flame region, where maximum temperatures are located.

- The overall flame temperature decreases with decreasing the fuel velocity (i.e. fuel mass flow rate).

- The higher the local temperature the stronger the main products formation. This is due to the local temperature directly affects the component rates of production and consumption.

- Increasing the air swirl number, the recirculation zone became stronger and the mixing rate increased results in small flame size, i.e., shorter flame length but wider flame diameter.

- Increasing the inlet air temperature leads to decreasing the flame length and the maximum temperature region is shifted up stream.

\section{References}

[1] Ilbas, M., Yı lmaza, I. and Kaplanb, Y., "Investigations of Hydrogen and HydrogenHydrocarbon Composite Fuel Combustion and $\mathrm{NO} x$ Emission Characteristics in A model Combustor", International Journal of Hydrogen Energy, Vol. 30, pp. 1139 -1147, (2005).

[2] Kontogeorgos, D. A., Keramida, E. P. and Founti, M. A., "Assessment of Simplified Thermal Radiation Models for Engineering Calculations in Natural gasFired Furnace", International Journal of Heat and Mass Transfer Vol. 50, pp. 5260-5268,(2007)

[3] Chan S.H., Pan X. C. and Abou-Ellail M. M. M., "Flamelet Structure of Radiating $\mathrm{CH}_{4}$-Air Flames", Combustion and Flame, Vol.102, pp. 438- 446, (1995).

[4] Carvalho M.G. and Farias T. L., "Modelling of Heat Transfer in Radiating and Combusting Systems", Trans IChemE, Vol. 76, pp. 175- 184, (1998).

[5] Guo H., Ju Y., Maura K., and Niioka T.,"Radiation Extinction Limit of Counter Flow Premixed Lean Methane - Air Flames", Combustion and Flame, Vol. 109, pp. 639-646, (1997).

[6] Ilbas, M., "The effect of Thermal Radiation and Radiation Models on Hydrogen-Hydrocarbon Combustion Modeling ", International Journal of Hydrogen Energy, Vol. 30, pp. 1113 - 1126, (2005).

[7] Lefebvre, A.H., "Gas Turbine Combustion". Hemisphere Publishing Corporation, first edition, (1983).

[8] Mellor, M., "Design of Modern Gas Turbine Combustors", Academic Press, (1990). 
[9] Syred, N., Beer, J.M.,"Combustion in Swirling Flows: A review", Combustion and Flame, Vol. 23, pp. 143-201, (1974).

[10] Ilbas, M., "CFD Prediction of Coupled Radiation Heat Transfer and Soot Production in Turbulent Flames", Twenty-Sixth Symposium (International) on Combustion/The Combustion Institute, pp. 23792386, (1996).

[11] Bakic, V., Belosevic, S., "Fuel-Air Ratio Influence on Mixing Processes Between Premixed Acetylene Flame and Surrounding Air", Thermal Sci., Vol.4 pp. 33-40, (2000).

[12] Kontogeorgos, D. A., Keramida, E. P. And Founti, M. A., "Assessment of Simplified Thermal Radiation Models for Engineering Calculations in Natural Gas-Fired Furnace", International Journal of Heat and Mass Transfer, Vol. 50, pp. 5260 - 5268, (2007).

[13] Keramida, E. P, Liakos, H. H., Founti, M. A., Boudouvis, A. G. And Markatos, N. C.,"Radiative Heat Transfer in Natural Gas - Fired Furnace", International Journal of Heat and Mass Transfer, Vol. 43, pp. 1801 - 1809, (2000).

[14] Mustafa Ilbas, "The effect of thermal radition and radition models on hydrogen - hydrocarbon combustion modelling", Int. J. of Hydrogen Energy, Vol. 30, pp. 1113-1126, (2005).

[15]Yı lmaz, I. And İ lbaş, M., "Experimental and Numerical Investigations of Methane Addition on Hydrogen Combustion in a Developed Combustor", International of Hydrogen Energy Congress and Exhibition Istanbul-Turkey, (2005).

[16] Fluent Program User Guide, September (2007).

[17] GAMBIT Program User Guide, September (2007). 